УДК 613.11:612.017.2

Ульяновская С.А., Баженов Д.В., Шестакова В.Г., Калинкин М.Н.

\title{
Влияние климатогеографических факторов Севера на адаптивные реакции организма человека
}

ФГБОУ ВО «Тверской государственный медицинский университет» Минздрава России,

170100, г. Тверь, Россия, ул. Советская, д. 4

В обзоре анализируется влияние климатогеографических факторов Севера на адаптивные реакции организма человека с позиций патологической физиологии. Основа адаптационных перестроек организма на Севере заключается в расширении физиологической нормы реакций и референсных пределов отдельных эндокринных и метаболических показателей. При выходе за пределы видовой нормы происходит снижение резервных возможностей организма, что приводит к патологии. Важную роль при этом играют внутригодовые колебания уровня гормонов, связанные с фотопериодикой. Ритмическая организация физиологических процессов имеет приспособительный характер, так как способствует подготовке и адаптации организма к условиям внешней среды в целях сохранения гомеостаза. Сезонные ритмы влияют на структуру и функцию всех систем организма человека. Многие патологические процессы в организме сопровождаются развитием десинхронозов. Рассогласование ритмов функционирования организма сопровождается нарушением исходной хроноструктурной организации физиологических реакций, что приводит не только к изменениям показателей функции эндокринной системы, но и к структурным изменениям в органах. Вопросы, рассмотренные в обзоре, отражают важность учета особенностей климатогеографических факторов Севера, приводящих к возникновению выраженных сдвигов в функционировании и структуре органов. Подтверждением вышесказанному является выявленный нами дисбаланс, в виде парциальной гипоплазии внешнесекреторного аппарата поджелудочной железы на фоне выраженного развития эндокринного компонента железы и стромы, это рассматривается как предпосылка для развития патологии. Анализ литературы показал также, что длительно действующий стрессовый фактор приводит к морфологической перестройке органов с адаптивными модификациями структуры.

Ключевые слова: десинхроноз; световой стресс; адаптивные модификации; полярные области; фотопериодизм.

Для цитирования: Ульяновская С.А., Баженов Д.В., Шестакова В.Г., Калинкин М.Н. Влияние климатогеографических факторов Севера на адаптивные реакции организма человека. Патологическая физиология и экспериментальная терапия. 2020; 64(1): 147-154.

DOI: 10.25557/0031-2991.2020.01.147-154

\author{
Для корреспонденции: Ульяновская Светлана Александровна, e-mail: ulyanovskayas@mail.ru \\ Финансирование. Исследование не имело спонсорской поддержки. \\ Конфликт интересов. Авторы заявляют об отсутствии конфликта интересов. \\ Поступила 01.07.2019 \\ Принята к печати 16.01.2020 \\ Опубликована 25.02 .2020
}

Ulyanovskaya S.A., Bazhenov D.V., Shestakova V.G., Kalinkin M.N.

Effect of the climatic and geographic factors of the North on adaptive reactions of the human body

Tver State Medical University,

Sovetskaya Str. 4, Tver 170100, Russia

Summary. The review analyzes effects of climatic and geographic factors of the North on adaptive reactions of the human body in terms of pathological physiology and morphology. The aim was to study adaptive reactions of the human body in the north to external factors, which include severe light and cold conditions. Methods. Analysis of current literature on the issue under study. Results. The adaptive rearrangement of the body in the North involves expanding physiological boundaries of individual endocrine and metabolic parameters. Beyond the normal limits of a species, the capacity of body reserve decreases, which may lead to a pathology. Of a great importance are intra-annual fluctuations of hormones associated with the photoperiodism. The rhythmic organization of physiological processes has an adaptive nature as it helps preparing and adapting the body to environmental conditions to maintain its homeostasis. Adaptive changes are known to occur not only at the level of physiological systems but also at the ultrastructural level. Seasonal rhythms affect the structure and function of all systems in the human body. Many pathological processes are associated with development of desynchronosis. Mismatching biorhythms under the action of exog- 
enous or endogenous factors is accompanied by disorders in the original chronostructural organization of physiological functions, which may leads not only to endocrine shifts but also to structural changes in organs. The review addresses the importance of taking into account the features of climatic and geographical factors of the North, which may induce pronounced changes in the structure and function of organs. The above-said is supported by the established imbalance evident as partial hypoplasia of the pancreatic exocrine apparatus associated with a pronounced endocrine component of the gland and stroma. These disorders are considered a prerequisite for development of abnormalities and may underlie congenital pancreatic pathology, such as fibrosis and diabetes. Conclusion. Long-acting stress factors lead to morphological rearrangements of organs and adaptive modifications of their structure.

Keywords: desynchronosis; light stress; adaptive modifications; polar regions; photoperiodism.

For citation: Ulyanovskaya S.A., Bazhenov D.V., Shestakova V.G., Kalinkin M.N. Effect of the climatic and geographic factors of the North on adaptive reactions of the human body. Patologicheskaya Fiziologiya i Eksperimental naya terapiya. (Pathological Physiology and Experimental Therapy, Russian Journal). 2020; 64(1): 147-154. (in Russian).

DOI: $10.25557 / 0031-2991.2020 .01 .147-154$

For correspondence: Svetlana A. Ulyanovskaya, Doctor of Medical Sciences, Head of the Department of Anatomy, 170100, Tver, ul. Sovetskaya, 4, Russia, e-mail: ulyanovskayas@mail.ru

Conflict of interest. The authors declare no conflict of interest.

Acknowledgments. The study had no sponsorship.

Information about authors:

Ulyanovskaya S. A., https://orcid.org/0000-0001-6600-4248

Bazhenov D. V., https://orcid.org/0000-0001-5160-7652

Shestakova V. G., https://orcid.org/0000-0003-1136-7396

Kalinkin M. N., https://orcid.org/0000-0001-5799-4147

Received 01.07.2019

Accepted 16.01.2020

Published 25.02.2020

Механизмы адаптации к условиям высоких широт представляют интерес для фундаментальной науки и практической медицины. Адаптивные реакции организма и их морфологический субстрат изучались в работах как отечественных, так и зарубежных морфологов, и физиологов [1-4].

Влияние факторов Севера как предпосылка физиологических изменений организа. По данным А.Б. Гудкова, О.Н. Поповой (2008) северные территории характеризуются суровыми климатогеографическими условиями, дискомфортными для проживания и трудовой деятельности. Выделяют специфические и неспецифические климатические факторы Севера. Специфическими для северных широт факторами считаются фотопериодизм, колебание атмосферного давления и электромагнитные факторы. Неспецифическими - холод, высокая влажность, тяжелый аэродинамический режим. Продолжительность светового дня на Севере значительно варьирует в течение года (полярная ночь и полярный день). Комплекс неблагоприятных факторов Севера оказывает непосредственное воздействие на организм через изменения его регуляторных систем [5].

Для регионов Севера характерно наличие перепадов влажности и температуры, частые колебания атмосферного давления, воздействие ветра. Согласно данным Н.П. Неверовой (1998), наиболее специфичными по физической природе и биологическим эффектам явля- ются космические и геомагнитные возмущения [6]. Как указывает Ю.Г. Мизун (1995), на Севере наблюдаются очень интенсивные электромагнитные поля, напряженность которых растет с увеличением географической широты, вследствие большой проницаемости для рентгеновских и гамма-лучей, радиоволн высокой и низкой частоты, электронов, протонов, нейтронов, ионов. При повышении солнечной активности происходит усиленное излучение электромагнитных волн и выброс заряженных частиц, которые воздействуют на белки системы тканевого дыхания и цепи электронного транспорта (цитохромы, цитохромоксидазу, железосернистые белки и др.) [7]. По мнению А.П. Жуковского с соавторами (1995), это приводит к изменению скорости переноса электронов по дыхательной цепи, в результате чего изменяется синтез АТФ, вслед за чем развивается каскад физиологических реакций [8].

Территории Севера отличаются недостатком ультрафиолета, особенно выраженным в период биологических сумерек, при преобладании рассеянной ультрафиолетовой радиации. В 1958 году В.Н. Кричагин указывал на то, что период «биологической тьмы» наступает при снижении суммарной ультрафиолетовой радиации даже в околополуденные часы. Ультрафиолетовое голодание влияет на энергообеспеченность клеток организма человека. В зимний период активируются свободно-радикальные процессы, снижается 
активность антиоксидантов, к которым относятся витамины C, E, D [9].

Таким образом, понятно, что комплексное воздействие неблагоприятных факторов Севера вызывает выраженные изменения в функционировании анатомофизиологических систем, что требует детального рассмотрения данного вопроса.

Ритмическая организация физиологических процессов. В современной литературе имеются публикации о том, что функционирование живого организма подчиняется «закону ритма» $[10,11]$. В последние десятилетия повышенное внимание уделяется изучению ритмической организации физиологических процессов организма в норме и патологии.

Отчетливо выражены ритмы с периодом 24 ч, названные Ф. Халбергом циркадианными. Суточный (24-часовой) ритм связан с вращением Земли вокруг оси. По аналогии с видимым светом ритмы с периодом более коротким, чем у циркадианных, названы ультрадианными, с более длинным - инфрадианными.

Циркадианную периодичность можно обнаружить в интегральных показателях жизнедеятельности: это и изменения работоспособности, церебральной и кардиальной гемодинамики, ортостатической устойчивости, сердечного цикла и дыхания, легочной вентиляции и потребления кислорода, а также функций системы пищеварения, концентрации макро- и микроэлементов, содержания аминокислот, медиаторов, половых гормонов, гормонов нейроэндокринной системы и др. [12]. Эти изменения обусловлены влиянием естественного освещения - фотопериодики. Циркадианная организация отражает генетически закрепленное приспособление организма к условиям жизни на Земле. Адаптация организма к условиям внешней среды необходима для поддержания его гомеостаза, чему способствует ритмическая организация физиологических процессов. Известно, что приспособительные перестройки происходят не только на уровне физиологических систем, но и на уровне ультраструктур клеток и тканей. По словам известного хронобиолога Г. фон Майерсбаха, микроскопическая структура клетки в течение суток изменяется до неузнаваемости [13].

Днем, в период активности, в организме увеличивается активность процессов потребления энергии, затрачиваемой на выполнение физической и умственной работы, при этом клетки, ткани, органы - «изнашиваются».

Ночью, во время отдыха, активно происходят процессы восстановления структур, деление клеток и организм восстанавливается. Параллельно с ритмическими изменениями функциональной активности систем ор- ганов, изменяется их чувствительность к воздействию внешних факторов. Следовательно, циркадианные ритмы функций организма имеют эндогенную природу.

Другая точка зрения свидетельствует о наличии синхронизаторов биоритмов, то есть о подверженности циркадианных ритмов внешним периодическим влияниям. Таким синхронизатором является супрахиазматическое ядро гипоталамуса, деятельность которого зависит от смены света и темноты. В ряде исследований имеются указания на связь циркадианных ритмов организма с суточной периодичностью средовых факторов, что подтверждает мнение о внешней экзогенной природе этих ритмов.

Таким образом, можно прийти к заключению, что ритмичность первоначально возникает как результат периодических воздействий среды, а в дальнейшем закрепляется генетически, и в настоящее время ритмы генерируются внутренним механизмом, но период их синхронизируется с частотой внешних стимулов.

Фотопериодика Севера и изменения физиологических показателей.

Хронобиологические закономерности регуляции функций организма основаны на определенных фазовых взаимоотношениях между биоритмами синтеза и продукции регуляторных факторов и биоритмами рецепторного аппарата. Ситуации, приводящие к изменению ритмов жизнедеятельности (широтные перелеты, миграции в контрастные поясно-временные и климатические регионы и пр.), являются факторами риска для развития изменений, вызывающих нарушения в деятельности основных регуляторных систем организма (нервной и эндокринной). Большое значение в адаптивных реакциях играют внутригодовые колебания уровней гормонов, связанных с фотопериодикой [3].

Анализ современной литературы по проблеме показал наличие при адаптации сдвига физиологических границ ряда эндокринных и иммунологических показателей. По мнению ряда авторов, успешная адаптация к внешним факторам обусловлена адекватной реакцией центральной нервной и гипоталамо-гипофизарно-адренокортикальной систем [14-16]. При срыве адаптации снижаются резервные возможности организма, что приводит к развитию патологии [17].

Работа эндокринной системы наиболее сбалансирована в периоды увеличения продолжительности дня и максимальном световом дне. В период уменьшения длительности светового дня и во время полярной ночи развиваются дисрегуляторные эндокринно-метаболические расстройства. В каждом периоде года определяется специфический метаболический профиль, и наблюдаются особенности гуморальной регуляции. В 
DOI: 10.25557/0031-2991.2020.01.147-154

период с октября по декабрь у северян происходит активация системы гипофиз - кора надпочечников и гипофиз - щитовидная железа. Одновременно снижается активность эндокринного аппарата поджелудочной железы, что приводит к повышению в крови содержания сывороточных триглицеридов, атерогенных фракций липидов и снижению уровня жирных кислот.

A. Holubová и соавт. (2016) на экспериментальном материале определили, что активация гипоталамо-гипофизарно-надпочечниковой системы важна для поддержания гомеостаза во время стресса как у взрослых крыс, так и у их потомства, что важно для адаптации новорожденных крысят. Данные свидетельствуют о том, что долгосрочные неонатальные стрессоры приводят к снижению чувствительности рецепторов АКТГ в коре надпочечников, что может быть предпосылкой для адаптации к стрессу во взрослой жизни [18].

В период с марта по июнь наблюдается высокая активность системы гипофиз - кора надпочечников и некоторое снижение функции щитовидной и поджелудочной желез, что сопровождается активизацией процессов этерификации холестерина, нарастанием в крови уровней глюкозы и свободных жирных кислот.

Для жителей Севера характерно сокращение срочных компенсаторно-приспособительных резервов инсулярного аппарата, проявляющееся повышением в крови уровня инсулина и снижением содержания кортизола. В контрастные периоды года (декабрь и июнь) пониженная толерантность к глюкозе компенсируется за счёт повышения содержания в сыворотке крови уровня тиреотропного и тиреоидных гормонов [19].

По данным В.В. Лупачева (2009), среднее количество андрогенов в крови русских мужчин - постоянных жителей Севера статистически значимо ниже значений, характерных для мужчин, проживающих в умеренном поясе. Все сезоны года, за исключением осени, сопровождаются снижением уровеня андрогенов в крови. Среднегодовое содержание липотропина у северян значимо выше такового у жителей средних широт. Усредненные значения фоликулостимулирующий гормон (ФСГ) значительно ниже общепринятой нормы и составляют около $32 \%$. Таким образом, наблюдается общая тенденция к изменению гормонального профиля системы «гипофиз - гонады». Минимизация функции звена «фоллитропин - тестостерон» сочетается с отчетливыми признаками дисфункции гормоногенеза ЛТ. Наиболее высокие уровни тестостерона наблюдаются в периоды убывания и нарастания светового дня. Для периода полярного дня характерны минимальные показатели тестостерона [20].
Д.Г. Губин и соавт. (2006) указывают на то, что системная интеграция физиологических процессов у многоклеточных организмов осуществляется посредством двух «дирижеров». Ведущими признаны парные супрахиазматические ядра гипоталамуса (СХЯ). СХЯ функционально и морфологически тесно связаны с центром гуморальной регуляции - эпифизом, который осуществляет координацию циркадианной системы посредством мелатонина. Эпифиз - это не единственное место продукции мелатонина, но именно мелатонин эпифизарного происхождения является основным источником, определяющим концентрацию мелатонина в плазме, и регулируется фотопериодикой. Одним из косвенных механизмов влияния мелатонина на суточный ритм биологических процессов является его способность оказывать гипотермическое действие [21].

Д.Б. Демин (2005) утверждает, что препубертатный и начало пубертатного периода у мальчиков, проживающих в условиях Севера, характеризуется напряжением гипофизарно - надпочечниковой системы. Для пубертата свойственно усиление обменных процессов, с активацией центрального звена эндокринной регуляции. Проявляются анаболические эффекты тиреоидных гормонов, соматотропина, пролактина и инсулина, что приводит к увеличению росто-весовых показателей. Уровни значений пролактина и инсулина у мальчиков-подростков, выше, чем у мальчиков-подростков, проживающих в умеренных широтах $[15,16]$.

Зимне-весенний период - это своеобразный подготовительный этап в обеспечении организма запасами пластического материала, необходимого для активных метаболических процессов в летний период. Поддержание гомеостаза в это время обеспечивается за счет усиления продукции инсулина. В контрастные периоды года (декабрь, июнь) наблюдается максимальная активность мощного регулятора углеводного и белкового обменов, гормона адаптации кортизола. Наибольшим стимулятором адаптационных возможностей растущего детского организма к климатическим условиям Севера на юге Архангельской области является инсулин, на Севере - кортизол.

В ряде работ морфологов и клиницистов Северных регионов [22-26] отмечается влияние сезонности и фотопериодизма на становление и функционирование структур эндокринной и фето-плацентарной систем. Клиницистами были выявлены пики фертильности в течение календарного года у женщин Архангельской области, во время которых зачатие приводит к наиболее благоприятным исходам беременности. При протекании второй половины беременности в наиболее неблагоприятные для Заполярья месяцы года, совпа- 
дающие с полярной ночью, у женщин, роды которых происходили в марте - апреле, чаще наблюдалась угроза прерывания беременности и развитие анемии. Снижение частоты осложнений беременности отмечено в июле-сентябре (в период полярного дня и смежного с ним периода белых ночей).

По мнению Р.В. Кубасова (2008), у жителей приполярных районов Северо-запада России имеются особенности сезонной динамики эндокринных функций. В период полярной ночи у местных жителей и коренных народностей содержание Т3 и Т4 выше, чем в период полярного дня. Имеются особенности годичных изменений уровней ТТГ и гормонов щитовидной железы у людей, живущих в сверхширотных зонах и на субарктических территориях. У мужчин, постоянно проживающих на территории Северной Финляндии в заполярье, минимальная концентрация свободного Т3 отмечена в феврале, а максимальная - в августе. Уровень ТТГ достигает максимума в декабре, а уровни общего и свободного Т4, а также общего Т3 не имеют выраженной сезонной ритмики. Определены сильные корреляционные связи уровня свободного Т3 и температуры воздуха, ТТГ и продолжительности светового дня, продолжительности светового дня и уровней гормонов щитовидной железы. Наблюдается окологодовая динамика уровней гонадотропных гормонов (лютеотропный, фолликулостимулирующий гормоны), пролактина, половых стероидов (тестостерон, прогестерон, эстрадиол). По характеру изменений авторами выделены две группы гормонов с сопоставимой динамикой: в первую входят гонадотропные гормоны, пролактин и прогестерон. Их наибольшие концентрации определяются в период минимальной продолжительности светового дня (декабрь) и ее увеличения (март). Ко второй группе относятся тестостерон и эстрадиол, максимальное содержание которых определяется в период наибольшей продолжительности светового дня (июнь), а минимальное - в период наименьшей ее длительности (декабрь) [27].

Все вышеуказанное свидетельствует о том, на Севере формируется особый гормонально-метаболический профиль, характеризующий изменения, происходящие в системе гипофиз - периферические железы при воздействии факторов Севера.

Морфологические проявления адаптации и десинхронозы. По мнению Академика РАН Н.А. Агаджаняна (2013), здоровье человека представляет собой оптимальное соотношение взаимосвязанных эндогенных ритмов физиологических процессов и их соответствие внешним циклическим изменениям. Рассогласование циркадианных ритмов организма в результате действия экзогенных или эндогенных раздражителей сопрово- ждается десинхронозом - нарушением исходной хроноструктурной организаци физиологических функций. Десинхроноз проявляется различными по характеру и степени выраженности вегетативными, иммунными, эндокринными нарушениями, расстройством деятельности сердечно-сосудистой, дыхательной, пищеварительной и других функциональных систем [17].

Практически все патологические процессы в организме проявляются нарушением временной организации физиологических функций, и в то же время рассогласование биоритмов может быть фоном для развития выраженных изменений деятельности организма. Если десинхронозы единичны, то организм через определенное время полностью восстанавливает свои функции.

По состоянию суточных ритмов физиологических функций можно судить об активности патологического процесса, поскольку степень проявления десинхроноза соответствует тяжести течения заболевания. По мнению Ф.И. Комарова (1989) многие патологические процессы в организме сопровождаются развитием десинхронозов. Десинхронозы наибольшее воздействие оказывают на эндокринные железы и поскольку эти железы принимают участие в росте и развитии организма, то морфологически это может проявляться либо ускорением, либо запаздыванием формирования органов и систем плода. Под действием факторов Севера изменяется функционирование всей системы гипофиз - периферические железы, в частности щитовидной железы, надпочечников, поджелудочной железы. Это является морфологической предпосылкой к развитию адаптивных реакций в северном варианте [11].

Морфологические изменения у лиц, проживающих в условиях Севера, являются областью интереса как отечественных, так и зарубежных ученых, данные вопросы изучаются как в эксперименте, так и в клинике. Длительное воздействие стрессирующих факторов Севера приводит к формированию адаптивных перестроек и северного адаптивного морфотипа. Влияние Севера на строение тела человека отражается сначала в функциональных перестройках, которые затем приводят к изменениям фенотипа популяции. Например, Ruff (1994) утверждал, что направленный отбор способствовал дифференциации большеберцовой кости, головки бедренной кости и ширины таза среди групп людей из разных географических регионов. Степень выраженности морфологических проявлений зависит от длительности проживания на севере [28-31].

В условиях Севера половое созревание (наиболее важный этап формирования функциональной активности женской половой системы), беременность и развитие плода происходит с значительными отличительны- 
ми особенностями по сравнению с жителями других климатических поясов [32-34]. В связи с этим, актуальной является концепция пренатального стресса, подробно изложенная К.Н. Ковровым (1997), в которой особый интерес представляют фетопатии, проявляющиеся в различных анатомо-физиологических системах плода дисплазиями и нарушениями хронологии становления органов и тканей. Такие сдвиги, по мнению ряда авторов, являются результатом катаболической стадии стрессорной реакции, первоначально начинавшейся вышеуказанными адаптивными модификациями [35].

Выявленный в исследованиях морфологов дисбаланс проявляется парциальной гипоплазией внешнесекреторного аппарата поджелудочной железы на фоне достаточного развития эндокринного компонента железы и выраженного развития стромы. На ранних этапах онтогенеза человека процесс развития поджелудочной железы в Северном регионе характеризуется четко выраженной возрастной динамикой и отсутствием гендерных отличий [36].

Таким образом, указанные изменения в поджелудочной железе при патологически протекающей беременности являются предпосылкой для развития патологии в будущем и могут лечь в основу врожденных нарушений поджелудочной железы, таких как фиброз и сахарный диабет.

По данным V. Vukicevic и соавт. (2015) и C. Steenblock и соавт. (2017) надпочечник представляет собой высокопластичный орган, способный адаптировать гомеостаз тела к различным физиологическим потребностям [37]. C. Drelon и соавт. (2015) утверждают, что надпочечники играют важную роль в контроле гомеостаза натрия и воды, реакции стресса, воспаления и обмена веществ, путем секреции глюкокортикоидов и минералокортикоидов [38].

В исследованиях Kristen R. R. Savell, Benjamin M. Auerbach, Charles C. Roseman (2016) показано влияние климатических условий на формирование адаптивных признаков, что подтверждается взаимосвязью между климатом и морфологическими различиями среди населения. Ассоциации между признаками и географической широтой явились результатом отбора по каждому индивидуальному признаку. Хотя многие параметры демонстрируют характер ответов на направленный выбор, соответствующий экогеографическим гипотезам [39].

Модели изменения формы структур человеческого тела, по-видимому, соответствуют экогеографическим ожиданиям, изложенным Бергманом и Алленом (1847) [40, 41].

Заключение. Обобщение результатов исследований морфологов и клиницистов позволяет сделать заключе- ние о том, что климатогеографические факторы Севера, основными среди которых являются холодовой фактор и световой стресс вызывают выраженные сдвиги в функционировании всех эндокринных желез, поджелудочной железы и надпочечников в частности. У людей, живущих на Севере, формируется особый гормонально-метаболический профиль, характеризующий изменения, происходящие в системе гипофиз - периферические железы. Ритмическая организация физиологических процессов способствует адаптации организма к условиям внешней среды. Приспособительные перестройки происходят не только на уровне физиологических систем, но и на уровне ультраструктур, клеток и тканей. Сезонные ритмы влияют на структуру и функцию всех систем организма человека. Многие патологические процессы в организме сопровождаются развитием десинхронозов. Подтверждением вышесказанному является выявленный нами дисбаланс, в виде парциальной гипоплазии внешнесекреторного аппарата поджелудочной железы на фоне выраженного развития эндокринного компонента железы и стромы, это рассматривается как предпосылка к развитию патологии в будущем и явиться основой врожденных нарушений поджелудочной железы. Длительно воздействующий стрессовый фактор приводит к морфологическим перестройкам органов и возникновению адаптивных модификаций структур органов.

\section{Участие авторов:}

Концепция и дизайн исследования - Ульяновская С.А., Баженов Д.В., Шестакова В.Г., Калинкин М.Н. Сбор и обработка материала - Ульяновская С.А. Написание текста - Ульяновская С.А.

Редактирование - Ульяновская С.А., Баженов Д.В., Шестакова В.Г., Калинкин М.Н.

\section{Литература}

1. Авцын А.П., Жаворонков А.А., Марачев А.Г., Милованов А.П. Патология человека на Севере. М.; Медицина, 1985.

2. Суханов С.Г. Влияние факторов крайнего Севера на женскую репродуктивную систему. 2013.

3. Ткачев А.В. Сезонная динамика эндокринных функций у человека на Севере. Физиология человека. 1987; 13(2): 328-30.

4. Ульяновская С.А., Суханов С.Г. Гипоплазия поджелудочной железы плодов и новорожденных Архангельской области как региональная особенность морфогенеза. В сб.: Актуальные проблемы морфологии. 2007; 137-40.

5. Гудков А.Б., Попова О.Н. Пульмонотропные факторы европейского Севера. Физиология. 2008; 2: 15-20.

6. Неверова Н.П. Активность электромагнитного поля Земли и здоровья человека в условиях Европейского Севера. Экология человека. 1998; 3: 21-4. 
7. Мизун Ю.Г. Влияние гелиофизических факторов на организм человека в условиях Крайнего Севера. Экология человека. 1995; 1: 42-9.

8. Жуковский А.П., Петров Л.Н., Ровнов Н.В. Биофизический механизм воздействия магнитного поля на живые организмы. В сб.: Проблемы охраны здоровья и социальные аспекты освоения газовых и нефтяных месторождений в Арктических регионах. Надым; 1995.

9. Кричагин В.Н. Нормирование УФ-лучей, применяемых в профилактических иелях. УФ-излучения. М.; 1958; 12-5.

10. Ежов С.Н. Основные концепции биоритмологии. Вестник ТГЭУ. 2008; 2: 104-21.

11. Комаров Ф.И., Романов Ю.А., Моисеева Н.И. Хрономедицина новое направление в медико-биологической науке и практике. В кн.: Хронобиология и хрономедицина. М.: Медицина, 1989; 5-17.

12. Катинас Г.С. Уровни организации живых систем и биологические ритмы. В кн.: Фактор времени в функциональной организации жииых систем. Л.; 1980; 82-5.

13. Алякринский Б.С., Степанова С.И. По закону ритма. М.; Наука, 1985.

14. Губарева Л.И. Экологический стресс. СПб; Лань, Ставрополь; Ставропольсервисшкола, 2001.

15. Демин Д.Б. Особенности становления гормонального статуса у мальчиков пубертатного периода, проживающих в южных районах Архангельской области. Экология человека. 2005; 5: 17-20.

16. Демин Д.Б., Поскотинова Л.В. Годичная ритмика секреции инсулина и кортизола у детей, проживающих на различных географических широтах Европейского Севера. Экология человека. 2007; 3: 20-3.

17. Агаджанян Н.А., Радыш И.В. Биоритмы. Среда обитания. Здоровье. М.; РУДН, 2013.

18. Holubová A., Štofková A., Jurčovičová J., Šlamberová R. The effect of neonatal maternal stress on plasma levels of adrenocorticotropic hormone, corticosterone, leptin, and ghrelin in adult male rats exposed to acute heterotypic stressor. Physiol Res. 2016; Dec. 22; 65.

19. Бичкаева Ф.А., Ткачев А.В., Бойко Е.Р., Третьякова Т.В., Кулакова И.В. Эколого-физиологические особенности обменных процессов в условиях Севера. В сб.: Медико-биологические и экологические проблемы здоровья человека на Севере. Сургут. 2002; Т.3: 5-7.

20. Лупачев В.В. Проблема репродуктивной функции особенности системы «гипофиз-гонады» у мужчин европейского Севера. Экология человека. 2009; 7: 20-3.

21. Губин Д.Г. Влияние фотопериодизма на циркадианные ритмы некоторых физиологических процессов. Роль мелатонина. В сб.: Здоровье и образование в 21 веке. 2006; Т. 8.

22. Коновалова С.Г., Конкиева Н.А. Экологическая морфология фетоплацентарной системы. Экология человека. 2005; 2: 17-24.

23. Милованов А.П. Системный подход в акушерстве с позиций. Вестник АМН. 1996; 2: 98-101.

24. Рогозин И.А., Лисица Г.П., Трещева Н.Д. Состояние репродуктивного здоровья женщин Севера европейской территории России. Экология человека. 1994; 1: 121-4.

25. Серов В.И., Сивочалова О.В., Кожин А.А. Методические аспекты исследований влияния экологических факторов на репродуктивную систему женщин. Акушерство и гинекология. 1990; 3: 6-9.

26. Ульяновская С.А., Баженов Д.В. Закономерности развития поджелудочной железы на Северо-западе России. Морфологические ведомости. 2013; 4: 87-92.

27. Кубасов Р.В. Цирканнуальная биоритмика гормональных показателей шитовидной и половых желез. Экология человека. 2008; 2: 26- 9.

28. Ткаченко Б.И. Физиологические основы здоровья человека. Учебник для мед. вузов. Архангельск: Изд. центр Север. гос. мед. унта, 2001.
29. Зенина О.Ю. Хронофизиология и хронопатология сердечнососудистой системы Экология человека. 2017; $1: 25-33$.

30. Kotelnikova S.V., Kargina M.V., Kotelnikov A.V. Morphofunctional state of the adrenal glands in albino rats under conditions of toxic stresscaused by cadmium salt in winter and summer periods. Bull. Exp. Biol. Med. 2011; Jun; 151(2): 250-2.

31. Ruff CB. Morphological adaptation to climate in modern and fossil hominids. Yearb Phys Anthropol. 1994; 37(S19): 65-107.

32. Айламазян Э. К., Беляева Т. В., Виноградова Е. Г. Новые принципы оценки экологической безопасности на основе комплекса показателей репродуктивной функции женщины. В сб.: Критерии экологической безопасности. СПб.; 1994; 106-7.

33. Губкина 3.Д. Адаптивные реакции эндокринной системы у жительниц Крайнего Севера. Российский физиологический журнал им. И.М. Сеченова. 2004; 8: 272.

34. Малявская С.И., Дворяшина И.В., Терновская В.А. Метаболический инсулинрезистентный синдром: диагностика, клиническое значение, педиатрические аспекты. Архангельск; СГМУ, 2004.

35. Ковров К.Н., Суханов С.Г. Морфологические особенности постнатальной перестройки эндокринно-иммунного комплекса новорожденных с высоким риском перинатальной патологии. В сб.: Труды 1 сбезда Российского общества патологоанатомов. 1996; 109-10.

36. Ульяновская С.А. Возрастная динамика органометрических показателей поджелудочной железы плодов. Морфология. 2014; 145; 3: 200.

37. Vukicevic V., Rubin de Celis M.F., Pellegata N.S. Adrenomedullary progenitor cells: Isolation and characterization of a multi-potent progenitor cell population. Mol Cell Endocrinol. 2015; Jun 15; 408: 178-84.

38. Drelon C., Berthon A., Mathieu M., Martinez A., Val P. Adrenal cortex tissue homeostasis and zonation: A WNT perspective. Bull Exp Biol Med. 2015 Nov; 160(1): 20-3.

39. Kristen R R Savell, Benjamin M Auerbach, Charles C Roseman. Constraint, natural selection, and the evolution of human body form. Proc Natl Acad Sci U S A. 2016; 081; 113(34): 9492-7.

40. Allen J.A. The influence of physical conditions on the genesis of species. Radical Rev. 1877; 1: 108-40.

41. Bergmann C. Über die Verhältnisse der wärmeökonomie der Thiere zu ihrer Grösse. Göttinger Studien. 1847; 3: 595-708.

\section{References}

1. Avtsyn A.P., Zhavoronkov A.A., Marachev A.G., Mylovanov A.P. The pathology of man in the North [Patologiya cheloveka na Severe]. Moscow, Meditsina Publ., 1985. (in Russian)

2. Sukhanov S.G. Influence of factors of the Far North on the female reproductive system /Vliyaniye faktorov Krainego Severa na zhenskuyu reproduktivnuyu sistemu]. M.; 2013. (in Russian)

3. Tkachev A.V. Seasonal dynamics of endocrine functions in humans in the North. Fiziologiya cheloveka. 1987, 13(2): 328-30. (in Russian)

4. Ulyanovskaya S.A., Sukhanov S.G. Pancreas hypoplasia of fetuses and newborns of the Arkhangelsk region as a regional feature of morphogenesis. Actual problems of morphology Collection of scientific papers. Ed. by N.S. Gorbunova. [V sbornike: Aktual'nye problemy morfologii. Sbornik nauchnykh trudov]. Pod red. N.S. Gorbunova. 2007: 137-40. (in Russian)

5. Gudkov A.B., Popova O.N. Pulmonotropic factors of the European North. Fiziologiya. 2008; (2): 15-20. (in Russian)

6. Neverova N.P. Activity of the Earth's electromagnetic field and human health in the conditions of the European North. Ekologiya cheloveka. 1998; 3: 21-4. (in Russian)

7. Mizun Y.G. The influence of heliophysical factors on the human body in the conditions of the Far North. Ekologiya cheloveka. 1995; 1: 429. (in Russian) 
8. Zhukovskiy A.P., Petrov L.N., Rovnov N.V. Biophysical mechanism of the magnetic field effect on living organisms. Problems of health protection and social aspects of development of gas and oil deposits in the Arctic regions [Problemy okhrany zdorovya i sotsial'nye aspekty osvoeniya neftyanykh mestorozhdeniy $v$ arkticheskikh regionakh]. Nadym, 1995. (in Russian)

9. Krichagin V.N. Rationing of UV rays used for preventive purposes. UV radiation. [Normirovaniye UF-luchey, primenyaemykh v profilakticheskikh tselyakh. UF-izlucheniya]. Moscow, 1958; 12-5. (in Russian)

10. Yezhov S.N. Basic concepts of biorhythmology. Vestnik TGEU. 2008, 2: 104-21. (in Russian)

11. Komarov F. I. Chronomedicine as a new trend in biomedical science and practice. In: Chronobiology and chronomedicine. [Hronobiologiya i khronomeditsina]. Moscow, Meditsina Publ., 1989: 5-17. (in Russian)

12. Katinas G.S. Levels of organization of living systems and biological rhythms. In: The time factor in the functional organization of living systems. [Faktor vremeni $v$ funktsional'noy organizatsii zhivykh system]. Leningrad, 1980: 82-5. (in Russian)

13. Alyakrinsky B.S. According to the law of rhythm [Po zakonu ritma]. Moscow; Nauka Publ., 1985. (in Russain)

14. Gubareva L.I. Ehkologicheskij stress. [Ecological stress]. St. Petersburg; Lan, Stavropol: Stavropolservis School; 2001. (in Russian)

15. Demin, D. B. Features of the formation of hormonal status in puberty period boys living in the southern areas of the Arkhangelsk region. Ekologiya cheloveka. 2005, no. 5, pp. 17-20. (in Russian)

16. Demin D.B., Poskotinova L.V. The annual rhythm of the secretion of insulin and cortisol in children living in different geographical latitudes of the European North. Ekologiya cheloveka. 2007, no. 3, pp. 20-3. (in Russian)

17. Agadzhanyan N.A., Radish I.V. Biorythms. Habitat. Health. [Bioritmy. Sreda obitaniya. Zdorovye]. Moscow; PFUR Publ., 2013. (in Russian)

18. Holubová A., Štofková A., Jurčovičová J., Šlamberová R. The effect of neonatal maternal stress on plasma levels of adrenocorticotropic hormone, corticosterone, leptin, and ghrelin in adult male rats exposed to the heterotypic stressor. Physiol Res. 2016. Dec. 22; 65.

19. Bichkayeva F.A., Tkachev A.V., Boyko E.R., Tret'yakova T.V., Kulakova I.V. Ecological and physiological features of metabolic processes in the North. Medical, biological and environmental problems of human health in the North. [Ehkologo-fiziologicheskie osobennosti obmennykh processov v usloviyakh Severa. Mediko-biologicheskie i ehkologicheskie problemy zdorov'ya cheloveka na Severe: materialy mezhdunarodnoy nauchnoy konferentsii]. Vol. 3. Surgut, 2002: 5-7. (in Russain)

20. Lupachev V.V. The problem of reproductive function of the "pituitary-gonadal" system in men of the European North. Ekologiya cheloveka. 2009; 7: 20-3. (in Russian)

21. Gubin D.G. et al. Influence of photoperiodism on the circadian rhythms of certain physiological processes. Health and education in the XXI century. [Role of melatonin. Zdorovye i obrazovaniye $v$ XXI veke]. 2006, vol. 8. pp. 210-1. (in Russian)

22. Konovalova S.G., Konkieva N.A. Ecological morphology of the fetoplacental system. Ekologiya cheloveka. 2005; 2: 17-24. (in Russian)

23. Milovanov A.P. System approach in obstetrics from the pathologist's position. Vestnik $A M N$. 1996; 2: 98-101. (in Russian)
24. Rogozin I.A. et al. The state of reproductive health of women of the North of the European territory of Russia. Ekologiya cheloveka. 1994; 1: 121-4. (in Russian)

25. Serov V.I. Methodological aspects of studies of the influence of environmental factors on the reproductive system of women. Akusherstvo i ginekologiya. 1990; 3: 6-9. (in Russian)

26. Ulyanovskaya S.A., Bazhenov D.V. Patterns of pancreas development in the North-West of Russia. Morfologicheskiye vedomosti. 2013; 4: 87-92. (in Russian)

27. Kubasov R.V. Circannual biorhythmics of hormonal parameters of the thyroid and sex glands. Ekologiya cheloveka. 2008; 2: 26-9. (in Russian)

28. Tkachenko B.I. Physiological basis of human health. [Fiziologicheskiye osnovy zdorovya cheloveka]. St. Petersburg-Arkhangelsk, SGMU Publ., 2001. (in Russian)

29. Zenina O.Y. et al.Chronophysiology and chronopathology of the cardiovascular system. Ekologiya cheloveka. 2017; 1: 25-33. (in Russian)

30. Kotelnikova S.V., Kargina M.V., Kotelnikov A.V. Morphofunctional state of the adrenal glands in albino rats under conditions of toxic stress by cadmium salt in winter and summer. Bull Exp Biol Med. 2011. Jun; 151 (2): 250-2.

31. Ruff CB. Morphological adaptation to climate in modern and fossil hominids. Yearb Phys Anthropol. 1994; 37 (S19): 65-107.

32. Ailamazyan E.K. New principles of environmental safety assessment on the basis of a complex of indicators of the reproductive function of a woman. Proceedings of the scientific-practical conference "Criteria of ecological safety” [Kriterii ekologicheskoy bezopasnosti: Materialy nauchnoprakticheskoy konferentsii]. St. Petersburg; 1994, pp. 106-7. (in Russain)

33. Gubkina Z.D. Adaptive reactions of the endocrine system in women of the Far North. Rossiyskiy fiziologicheskiy zhurnal im. I.M. Sechenova. 2004; 8: 272. (in Russian)

34. Malyavskaya S.I., Dvoryashina I.V., Ternovskaya V.A. Metabolic insulin-resistant syndrome: diagnosis, clinical significance, pediatric aspects [Metabolicheskiy insulinresistentnyy sindrom: diagnostika, klinicheskoye znacheniye, pediatricheskiye aspekty]. Arkhangelsk, SGMU Publ., 2004. (in Russian)

35. Kovrov K.N., Sukhanov S.G. Morphological features of postnatal adjustment of the endocrine-immune complex of newborns with a high risk of perinatal pathology. In the collection: Proceedings of the 1st congress of the Russian Society of Pathologists. [V sbornike: Trudy $1 \mathrm{~s}$ "ezda Rossiyskogo obshchestva patologoanatomov]. 1996; P. 109-10. (in Russian)

36. Ulyanovskaya S. A. Age dynamics of the organometric parameters of the fetal pancreas. Morfologiya. 2014; 145(3): 200-1. (in Russian)

37. Vukicevic V., Rubin de Celis M.F., Pellegata N.S. et al. Adrenomedullary progenitor cells: Isolation and characterization of a multi-potent progenitor cell population. Mol Cell Endocrinol. 2015, Jun 15; 408: 178-84.

38. Drelon C., Berthon A., Mathieu M., Martinez A., Val P. Adrenal cortex tissue homeostasis and zonation: A WNT perspective. Bull Exp Biol Med. 2015 Nov; 160(1): 20-3.

39. Kristen R R Savell, Benjamin M Auerbach, Charles C Roseman. Constraint, natural selection, and the evolution of the human body form. Proc Natl Acad Sci USA. 2016. 08; 1; 113 (34): 9492-7.

40. Allen J.A. The influence of physical conditions on the genesis of species. Radical Rev. 1877; 1: 108-40.

41. Bergmann C. Über die Verhältnisse der wärmeökonomie der Thiere zu ihrer Grösse. Göttinger Studien. 1847; 3: 595-708.

Сведения об авторах:

Ульяновская С.A., доктор мед. наук, доцент, зав. каф. анатомии ФГБОУ ВО «Тверской ГМУ» Минздрава России;

Баженов Д.В., доктор мед. наук, чл.-корр. РАН, проф. каф. анатомии ФГБОУ ВО «Тверской ГМУ» Минздрава России; Шестакова B.Г., канд. биол. наук, доцент, зав. каф. гистологии, эмбриологии и цитологии ФГБОУ ВО «Тверской ГМУ» Минздрава России;

Калинкин М.Н., доктор мед. наук, проф., зав. каф. патологической физиологии ФГБОУ ВО «Тверской ГМУ» Минздрава России. 